\title{
Review and Analysis of the Journal of College Counseling: 1998-2005
}

\author{
James M. Benshoff and Lisa J. Flint
}

The Journal of College Counseling (JCC) began its life in 1995 with the appointment of a founding editor and its Ist editorial board. The Ist semiannual issue of the journal was published in spring 1998, and the journal has continued to be published twice each year since then. This article presents an analysis and discussion of the content of the first 15 issues of JCC. Implications and recommendations for the future of the journal are discussed.

7 he American College Counseling Association (ACCA) was chartered in 1991 as a division of the American Counseling Association (ACA) with a focus on fostering student development in colleges, universities, and community colleges. Following the disaffiliation of the American College Personnel Association as a division of ACA, ACCA was created to provide a professional "home" for counselors who work in higher education settings. The mission of ACCA (n.d.), as stated on the association's Web site, is as follows:

\begin{abstract}
The American College Counseling Association is a national organization for persons in higher education settings whose professional identity is counseling and whose purpose is fostering student development. ACCA strives to support and enhance the practice of college counseling, to promote ethical and responsible professional practice, to promote communication and exchange among college counselors across service areas and institutional settings, to encourage cooperation with other organizations related to higher education and college student development, and to provide leadership and advocacy for the professional of Higher Education. (para. 1)
\end{abstract}

To further the association's mission, the executive board of ACCA voted to create a professional journal as a service to members and as a forum for research and scholarship related to college counseling. In summer 1995, James M. Benshoff was appointed as founding editor and provided with a budget to begin setting up operations. The next few months included not only issuing calls for manuscript submissions but also appointing a board of editorial reviewers; hiring and training an editorial assistant; and establishing procedures for processing, reviewing, and determining acceptance of manuscripts The first issue of the journal was sent to the publisher (ACA) in late 1997, and Volume 1, Issue 1, was first sent to ACCA members and subscribers in spring 1998.

In the "President's Message" from the first issue of the Journal of College Counseling (JCC), Mattox (1998) stated that JCC was "a goal of ACCA from the moment ACCA was conceived" (p. 6) with a primary purpose of serving as "a

James M. Benshoff and Lisa J. Flint, Department of Counseling and Educational Development, The University of North Carolina at Greensboro. Lisa J. Flint is now with the North Carolina State Government Internship Program, Raleigh, North Carolina. Correspondence concerning this article should be addressed to James M. Benshoff. Department of Counseling and Educational Development, The University of North Carolina at Greensboro, PO Box 26170, Greensboro, NC 27402 (e-mail: benshoff@uncg.edu).

(C) 2006 by the American Counseling Association. All rights reserved. 
tool for practitioners" (p. 6). In the same issue, Davis (1998) emphasized the perceived need within ACCA for "a professional journal [reflective of] the guiding principles of the organization and the diverse roles, interests, and settings of [ACCA] membership" (p. 9). Benshoff(1998) characterized the "development of a professional journal [as] a critical step in an association's evolution" (p. 4) and acknowledged the role of a journal in helping to advance the profession. The initial vision, "to create a professional publication that recognizes the importance and potential contributions of both research and practice to our profession" (Benshoff, 1998, p. 4), was evident in two key aspects of the journal. First, three sections of the journal were created to accommodate different types of articles: Research, Professional Issues, and Innovative Practice. Second, authors were instructed to clearly address implications for the practice of college counseling in all three types of articles.

During its relatively short life, JCC has had four editors: James M. Benshoff (19961999), N. Carolyn Owens (1999-2001), Timothy B. Smith (2001-2004), and Laura Hensley Choate (2004-2007). All of these editors have been active ACCA members, and three of the four have been counselor educators. (N. Carolyn Owens began her editorship as a student affairs professional who crossed over to become a faculty member in the 2 nd year of her term.) Since the journal's beginning, it has been published and distributed by ACA. Each of the editors has continued to emphasize the need for all articles published in JCC to clearly address implications for college counseling practitioners. The journal's acceptance rate of $15 \%$ (C. Baker, personal communication, July 21,2005 ) is typical of ACA journals and reflects the care and discrimination with which articles are reviewed and accepted for publication.

Although $J C C$ has had a short but rich history, there previously has not been a systematic examination of the content of the journal. This study is similar in purpose to content reviews conducted by other professional journals. The specific purposes of this study were (a) to review and examine articles published in the first 15 issues of JCC and (b) to examine membership on the journal's editorial board during that same period. In this study, we sought to examine types, topics, and authorship of articles published in JCC with the goal of presenting a summary of these and an overview of the content and focus of the journal during its first 7 years in print. Such information about the content of the journal since its first issue can be helpful to authors interested in a summary of topics previously published by $J C C$ as well as to editors and editorial board members who help to determine the balance of topics and types of articles that should be published in the journal. Similarly, another goal was to take a broad look at the composition of the editorial board since the journal's inception and provide a descriptive summary to help provide future direction for JCC in ensuring diversity in the ethnicity and professional position of reviewers appointed to the journal's board.

\section{Method}

The sample for this review included all published articles from JCC from its inception in the spring of 1998 up to and including the Spring 2005 issue. This resulted in a review of 138 articles from 15 issues, exclusive of editorials. Each article was 
initially reviewed for the section of the journal in which it appeared, type of article, author information, topic and relevant student population, and theoretical basis.

Article type was denoted by the section of the journal in which it was published (Research, Professional Issues, or Innovative Practice). The existence of empirical research contributions was also noted. Information about authors was recorded, including author's professional affiliation or position.

The subject matter of each article was noted and categorized into 20 topic categories. We independently reviewed each article and made notes on each article's general topic(s); this list of general topics was then collapsed into common themes. After we reviewed the body of articles and independently categorized them, together we determined the final list of 20 categories. Agreement was high between our initial general categories. Several articles potentially fit into more than one category (e.g., career concerns of nontraditional students), and, following discussion, we placed the articles in the category that best matched the primary focus of the article. It should be noted that this analysis was a qualitative process and could be skewed by placement of articles in secondary or other relevant topic categories. For each topic category, the number of articles was noted, as well as the issues and journal sections (e.g., Innovative Practice) in which the topic was covered. In addition to the topic of the article, the specific student population being addressed was noted when applicable, because a number of articles addressed a specific subpopulation of college students, such as women, student athletes, or international students. Seventy-six articles (55\%) focused on some type of special population or subgroup of college students.

Because the nature of membership on editorial boards is an important consideration in the life of a professional journal, we also reviewed JCC's editorial board composition from 1995 to 2005 . This involved reviewing names, gender, and institutional affiliations of professionals who served on JCC's editorial board during that period. Unlike the analysis of published articles, this period began in 1995 when the first review board members were appointed by ACCA.

\section{Results and Discussion}

\section{Composition of Journal}

From spring 1998 to spring 2005 , approximately half $(n=73,53 \%)$ of the published articles in JCC were empirical, research-based contributions. The other half focused on counseling practice and professional concerns, consisting of articles published in the Innovative Practice $(n=28,20 \%)$ and Professional Issues $(n=31,23 \%)$ sections and in a special section devoted to nontraditional students $(n=6,4 \%)$.

Each issue to date has contained between 7 and 11 articles. As might be expected, fewer articles $(n=15)$ were published in the journal's lst year, whereas a steady number of articles have been published each year from 1999 to the present (ranging from 16 to 21 articles per year). Variations in quantity over time have resulted primarily from the varying numbers of articles published in the Innovative Practice and Professional Issues sections. The number of Research section articles has been steady each year (ranging from 7 to 11 articles per year). The greatest variation 
in the number of articles published was in the Innovative Practice section, where the number of articles published ranged from a low of 1 in 1998 to a high of 8 in 2001. Four Innovative Practice articles per issue were published that year.

Also noteworthy is the publication of JCC's first special section, which appeared in the Spring 2004 issue, with Atticia P. Bundy as the guest editor. This special section included six articles focused on effective strategies for counseling nontraditional students. Bundy and Smith (2004) cited the need for quality articles on this topic, given that "nontraditional students currently compose at least $40 \%$ and as much as $70 \%$ of all undergraduate students nationwide, depending on how the term nontraditional is defined" (p. 3). Although not included in this analysis, a second special section (Severe and Persistent Mental Illness on College Campuses) was published in the Fall 2005 issue. Special sections should continue to be considered as a way to provide a more intensive focus on important issues or specific student populations in future issues of the journal.

The overall trend in article quantity and balance discussed in this review indicates consistency with the founding editor's vision (Benshoff, 1998), given that the journal has been providing consistent empirical and practical contributions to the field of college counseling. Table 1 presents more specific information on the type and number of articles by year, volume, and issue. In a journal that is targeted primarily to practitioners, it might be expected that the number of Innovative Practice and Professional Issues articles would be higher. If quality of manuscripts submitted for these two sections has not been a significant issue, editors may need to be more proactive in encouraging submissions for these sections. It should be noted, however, that JCC appears to have succeeded in attracting quality research manuscripts on a wide variety of issues and populations in higher education settings.

\section{Published Topics and Trends}

The topics of published articles in JCC were reviewed for overall trends and shifts over time. Articles from spring 1998 to spring 2005 were classified into 20 categories (see Table 2 ). Even a cursory review of these categories reveals the breadth of relevant topics to college student populations that have been addressed in JCC. Several themes emerged from reviewing the topics of articles over time. In general, a rich sample of current issues relevant to college student populations has been addressed in some manner in the journal.

Overall, a review of the content of $J C C$ indicates an appropriate and fairly comprehensive survey of current relevant topics in college counseling. Approximately $35 \%$ of the published articles reviewed were specifically grounded in a student development or counseling theory. Theoretical bases for the articles stemmed from a wide range of student development and counseling theories and models, including Chickering's 7-Vector Model of College Student Development, Tinto's Model of Student Attrition, motivational interviewing, life span development models (e.g., Erikson), racial identity models, feminist theory, moral development theories (e.g., Kohlberg or Gilligan), and wellness models. One of the challenges in preparing college counselors is helping them understand the importance of understanding and applying both student development 
TABLE 1

Type and Number of Articles by Year, Volume, and Issue

\begin{tabular}{|c|c|c|c|c|c|}
\hline \multirow[b]{2}{*}{$\begin{array}{l}\text { Year, Volume, } \\
\text { and Issue }\end{array}$} & \multicolumn{4}{|c|}{ Type of Article } & \multirow[b]{2}{*}{$\begin{array}{c}\text { No. of } \\
\text { Articles }^{a}\end{array}$} \\
\hline & $\begin{array}{c}\text { Innovative } \\
\text { Practice }\end{array}$ & $\begin{array}{c}\text { Professional } \\
\text { Issues }\end{array}$ & Research & $\begin{array}{l}\text { Special } \\
\text { Section }\end{array}$ & \\
\hline \multicolumn{6}{|l|}{1998} \\
\hline Vol. 1 , No. 1 & 1 & 1 & 6 & 0 & 8 \\
\hline Vol. 1, No. 2 & 0 & 3 & 4 & 0 & 7 \\
\hline \multicolumn{6}{|l|}{1999} \\
\hline Vol. 2, No. 1 & 2 & 3 & 5 & 0 & 10 \\
\hline Vol. 2, No. 2 & 3 & 2 & 4 & 0 & 9 \\
\hline \multicolumn{6}{|l|}{2000} \\
\hline Vol. 3 , No. 1 & 2 & 1 & 5 & 0 & 8 \\
\hline Vol. 3 , No. 2 & 0 & 2 & 6 & 0 & 8 \\
\hline \multicolumn{6}{|l|}{2001} \\
\hline Vol. 4 , No. 1 & 4 & 2 & 4 & 0 & 10 \\
\hline Vol. 4, No. 2 & 4 & 1 & 6 & 0 & 11 \\
\hline \multicolumn{6}{|l|}{2002} \\
\hline Vol. 5, No. 1 & 1 & 2 & 5 & 0 & 8 \\
\hline Vol. 5, No. 2 & 3 & 3 & 5 & 0 & 11 \\
\hline \multicolumn{6}{|l|}{2003} \\
\hline Vol. 6, No. 1 & 1 & 4 & 4 & 0 & 9 \\
\hline Vol. 6 , No. 2 & 1 & 3 & 5 & 0 & 9 \\
\hline \multicolumn{6}{|l|}{2004} \\
\hline Vol. 7, No. 1 & 2 & 0 & 3 & 6 & 11 \\
\hline Vol. 7, No. 2 & 4 & 2 & 4 & 0 & 10 \\
\hline \multicolumn{6}{|l|}{2005} \\
\hline Vol. 8, No. 1 & 0 & 2 & 7 & 0 & 9 \\
\hline Total & 28 & 31 & 73 & 6 & 138 \\
\hline
\end{tabular}

aRepresents total number of articles per issue.

and counseling theories in their actual practice. Thus, it seemed important to review all the articles published in the first 15 issues of JCC to determine to what extent theories actually were used as a basis for research and practice.

Categories with the most total contributions included multicultural and international students and counseling approaches and outcomes (each representing $10.1 \%$ of total published articles), followed by client attitudes and preferences, alcohol-related concerns, and professional and institutional issues, each of which represented $8.0 \%$ of total published articles. Each of these categories was consistently covered in each year of publication. A commitment to the needs of diverse populations is evident upon review of the journal's content over the past 7 years, which addresses concerns related to a wide variety of ethnic and racial student groups. Articles in the counseling approaches and outcomes category were those that discussed or reviewed a specific approach to counseling, model, or outcome(s) of counseling. The prevalence of this type of writing is consistent with the intended practical orientation of the journal. JCC has also consistently published articles that address alcohol and drinking, a prominent topic of concern in college counseling. The publication of nine professional and institutional issues articles (including four research-based articles) suggests the significance of these issues for college counselors. 


\section{TABLE 2}

\section{Articles by Topic Category, Spring 1998-Spring 2005}

\begin{tabular}{lcc}
\hline \hline Category & No. of Articles & $\begin{array}{c}\text { \% of Total } \\
\text { Articles }\end{array}$ \\
\hline Multicultural and international students & 14 & 10.1 \\
Counseling approaches and outcomes & 14 & 10.1 \\
Client attitudes and preferences & 11 & 8.0 \\
Alcohol-related concerns & 11 & 8.0 \\
Professional and institutional issues & 11 & 8.0 \\
Academic concerns & 10 & 7.2 \\
Outreach and programming & 9 & 6.5 \\
Eating disorders and body image & 7 & 5.1 \\
Relationship concerns & 7 & 5.1 \\
Sexual aggression & 6 & 4.3 \\
Career concerns & 6 & 4.3 \\
Wellness & 6 & 4.3 \\
Clinical issues & 5 & 3.6 \\
Assessment & 4 & 2.9 \\
Gay, lesbian, bisexual, and transgender students & 4 & 2.9 \\
Nontraditional students & 3 & 2.2 \\
Student athletes & 3 & 2.2 \\
Students with disabilities & 3 & 2.2 \\
Online service delivery & 2 & 1.4 \\
Spirituality and religion & 2 & 1.4 \\
\hline
\end{tabular}

Note. Percentages do not equal $100 \%$ because of rounding.

JCC has also demonstrated a willingness to publish articles that explore and discuss new trends in college student populations and college counseling services. The review of journal content demonstrates this in two ways. As previously noted, JCC has published one special section in 2004 focused on nontraditional students, an ever-growing student population in American higher education. Prior to this special section, just two articles had been published in JCC that specifically addressed the nontraditional student population. One of these articles (Foltz \& Luzzo, 1998) appeared in the initial issue and explored career decision making; the spring 2002 article addressed retention (Leonard, 2002). Second, the first two articles related to online service delivery were published in the Fall 2004 issue, one exploring a diverse client group's attitudes in using Internet technology for counseling (Chang \& Chang, 2004) and the other discussing the implementation of online programming (Lynch \& Kogan, 2004). The aforementioned types of articles indicate that JCC's content tends to reflect current trends and innovations in the practice of college counseling.

Some topic categories, however, may deserve further attention in future submissions. For example, only two articles related to the topic of spirituality and religion were published, one in 2002 (Weinstein, Parker, \& Archer, 2002) and the other in 2004 (Aten, 2004). In addition, no articles on career development of college students were published in 1999,2000 , or 2001 , although this may be due in part to the large amount of literature focusing specifically on career counseling that has been published in career journals. Also not published during 1999-2001 were articles related to wellness issues. In categories with five or fewer published articles (i.e., clinical issues; assessment; gay, lesbian, bisexual, and transgender students; 
nontraditional students; student athletes; students with disabilities; online service delivery; and spirituality and religion), it is notable that these categories were each recently addressed in the Spring 2004, Fall 2004, or Spring 2005 issues.

\section{Authorship}

Authors published in JCC came from a variety of disciplines and included a mixture of practitioners and faculty. Nearly half $(45 \%)$ of the published articles had two or more authors from different fields (e.g., counseling and psychiatry) or positions (e.g., faculty and practitioner). This suggests a significant level of interdisciplinary work or cooperation between faculty members and college counseling practitioners. Authors primarily came from the profession of counseling, followed closely by psychology and then a variety of other fields, such as psychiatry, education, human development, social work, and medicine. A majority (83\%) of articles had a faculty member or doctoral student listed as first author. Thus, there has been considerable collaboration among different types of authors in JCC over the past 7 years. This still suggests that greater untapped opportunity exists for submissions by practitioners, administrators, and others in the field.

\section{Editorial Review Board Composition}

The first editorial review board for the journal was created in fall 1995 , with reviewers selected from applications received in response to a call for reviewers published in the ACCA newsletter and on the ACCA Web site. Selections were made by the editor, with approval and appointment from the ACCA board (or ACCA-designated representative). In appointing reviewers to the JCC board, particular attention was given to their records of publication, ACCA membership, and region (in an effort to be as representative as possible of the geographic locations of ACCA members and journal readers). Since 1996, all five ACA regions have been consistently represented on the JCC board, with most reviewers coming from the three largest regions: the Southern Region, the North Atlantic Region, and the North Central Region. Only one international member (from Korea) has served on the review board.

The first board consisted of only 21 members ( 8 women, 13 men); several adjunct reviewers were also used to handle the high volume of submissions at times. Since that lst year, however, the size of the JCC editorial board typically has ranged from 24 to 36 reviewers. The percentage of female reviewers has ranged from $38 \%$ to $44 \%$. No data have been collected on the ethnicity of reviewers or their professional position. Not surprisingly, the majority of reviewers clearly appear to be faculty members who are accorded time and credit for service on an editorial board. This is less likely to be true for practicing college counselors, who may also be more likely to find it difficult to make time for research and writing on their own. At least one or two board members have been doctoral students at the time of their appointment to the board. Reviewers have come from all types of higher education institutions, ranging from small, private schools to large, public schools. The emphasis in the journal has 
been on 4-year institutions; thus, it is not surprising that only a handful $(n<5)$ of reviewers have been from community colleges or other institutions (e.g., the Korean Youth Counseling Institute).

One of the challenges for any editor is finding and developing editorial board members who will take the time to provide useful critical feedback to authors and review manuscripts in a timely manner. This problem is not unique to JCC, because there has been discussion among other editors of other journals and doctoral faculty in recent years about how to cultivate and prepare competent reviewers and future editors, an issue that is likely to continue to receive attention. In general, however, JCC consistently has attracted a dedicated group of competent and qualified reviewers with a commitment to serving the profession and the association through their work with the journal.

\section{Summary and Conclusion}

As noted earlier, the journal seems to be meeting its stated goals and objectives. Overall, JCC has demonstrated a heavy emphasis on topics related to counseling centers and clinical issues or interventions. Several opportunities may exist to further expand the journal's scope as it pertains to the field of college counseling. For example, little has been published in JCC relating to residence life, student activities, or judicial affairs. One reason for this may be the existence of journals devoted to those specific areas of student affairs as well as there being more established journals such as the Journal of College Student Development and the NASPA Journal. Moreover, the emphasis of the journal on "college counseling" may imply a more "counseling center" focus and discourage submissions from college counselors working in areas such as residence life and student activities. At a recent meeting, the JCC board determined that student affairs articles not specifically related to the practice of college counselors are not within the scope of the journal. It will be important, however, for JCC to continue to consider articles that represent the full scope of practice of those professionals who identify themselves as college counselors. Areas such as study abroad and experiential education (e.g., leadership and service-learning programs) are becoming increasingly prevalent on campuses and deserve attention in future issues of JCC. Student learning experiences such as these present new opportunities for college counselors (e.g., reentry counseling for students returning from study abroad experiences).

One gap in the journal's content has been in addressing specific issues and concerns in community colleges. One empirical article (Bundy \& Benshoff, 2000 ) was published in the Fall 2000 issue regarding perceptions of personal counseling services in community colleges. As a primary and unique part of the higher education system, community colleges may warrant particular attention because counselors in these settings may benefit from specialized information and research that will help them best serve their students. In fact, the Bundy and Benshoff article noted the need for more counseling services in community colleges and more expanded roles for community college counselors. 
Another area of concern on college campuses that has not been addressed directly in any JCC articles from 1998 to 2005 has been drug-related issues. Although several articles have focused on alcohol-related issues in higher education, drug use on campus has received no specific attention in JCC. Clearly, this is a critical issue that could benefit from both practical how-to articles and research-based articles.

A critical consideration for any professional journal is review time-the length of time between receipt of a manuscript and communication of a decision to the author(s). Keeping review time to a minimum is increasingly a key factor that can positively or negatively affect the journal's reputation, thereby having an impact on the number and quality of manuscript submissions. Anecdotal evidence seems to indicate that lengthy review periods have been the exception rather than the norm with JCC. Finally, in terms of the composition of the review board, JCC could benefit from having more college counseling practitioners and more members from underrepresented groups as part of the editorial review team. In the future, the journal should collect more data about the professional position and ethnicity of reviewers to ensure diverse representation on the board. Clearly, JCC has made a place for itself in the world of professional publications by consistently publishing high-quality articles on a wide variety of topics relevant to college counseling, including a substantial percentage of research-based articles.

\section{References}

American College Counseling Association. (n.d.). Welcome to the American College Coutnseling Association. Retrieved June 10, 2005, from http://www.collegecounseling.org

Aten, J. D. (2004). Improving understanding and collaboration between campus ministers and college counseling center personnel. Journal of College Counseling, 7, 90-96.

Benshoff, J. M. (1998). On creating a new journal for college counseling. Journal of College Counseling, 1, 3-4.

Bundy, A. P., \& Benshoff, J. M. (2000). Students' perceptions of need for personal counseling services in community colleges. Journal of College Counseling, 3, 92-99.

Bundy, A. P., \& Smith, T. B. (2004). Breaking with tradition: Effective counseling services for nontraditional students. Journal of College Counseling, 7, 3-4.

Chang, T., \& Chang, R. (2004). Counseling and the Internet: Asian American and Asian international college students' attitudes toward seeking online professional psychological help. Journal of College Counseling, 7, 140-149.

Davis, D. C. (1998). The American College Counseling Association: A historical view. Journal of College Counseling, 1, 7-9.

Foltz, B. M., \& Luzzo, D. A. (1998). Increasing the career decision-making self-efficacy of nontraditional college students. Journal of College Counseling, 1, 35-44.

Leonard, M. Q. (2002). An outreach framework for retaining nontraditional students at openadmissions institutions. Journal of College Counseling, 5, 60-73.

Lynch, S. K., \& Kogan, L. R. (2004). Designing online workshops: Using an experiential learning model. Journal of College Counseling, 7, 170-176.

Mattox, B. (1998). President's message. Journal of College Counseling, 1, 5-6.

Weinstein, C. M., Parker, J., \& Archer, J., Jr. (2002). College counselor attitudes toward spiritual and religious issues and practices in counseling. Journal of College Counseling, 5, $164-174$. 